\title{
Publisher's Note: Evolution of damping in ferromagnetic/nonmagnetic thin film bilayers as a function of nonmagnetic layer thickness [Phys. Rev. B 93, 054402 (2016)]
}

S. Azzawi, A. Ganguly, M. Tokaç, R. M. Rowan-Robinson, J. Sinha, A. T. Hindmarch, A. Barman, and D. Atkinson (Received 3 June 2016; published 13 June 2016)

DOI: 10.1103/PhysRevB.93.219902

This paper was published online on 1 February 2016 with an incorrect figure. Figure 4 has been replaced as of 2 June 2016. The figure is incorrect in the printed version of the journal; therefore for the benefit of the print readership, the figure and its caption are replicated below.
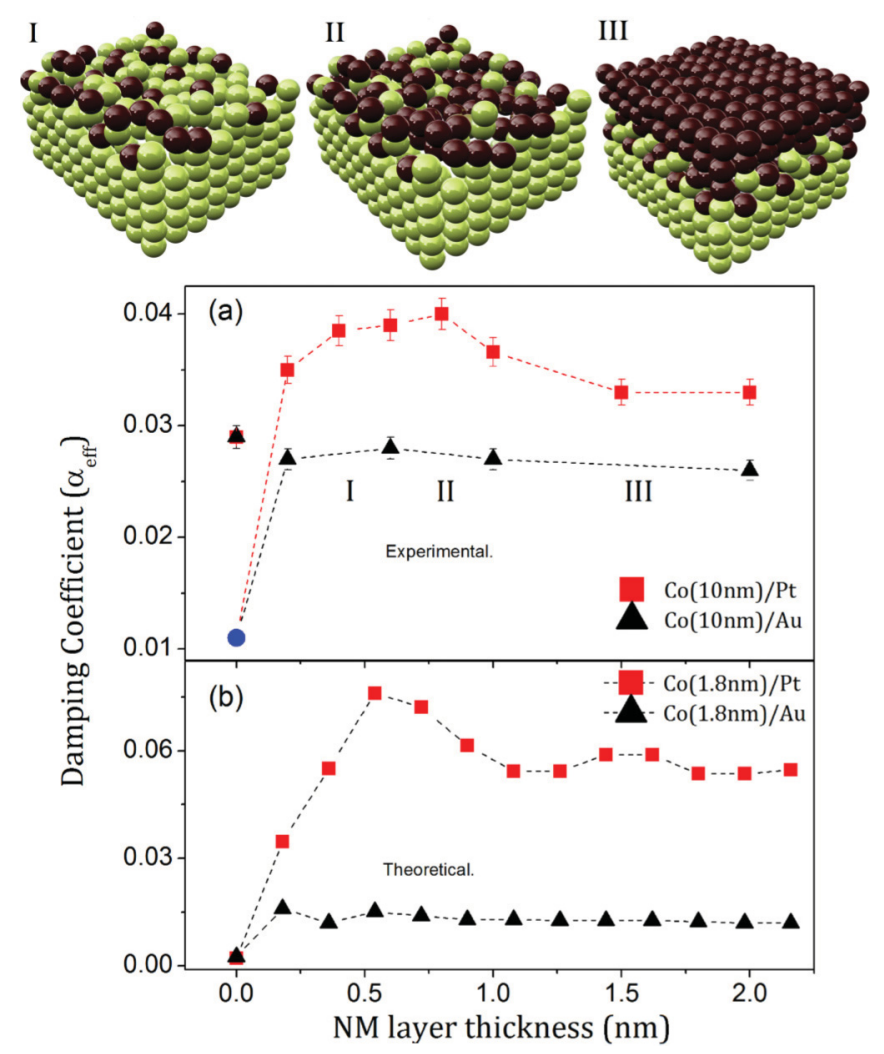

FIG. 4. Schematic illustration of the growth of discontinuous to continuous NM capping layer. (a) Experimental damping data for Co/Pt and $\mathrm{Co} / \mathrm{Au}$ as a function of $t_{\mathrm{NM}}$. The circular point is a literature value for pure cobalt. (b) Theoretical variation in damping data for $\mathrm{Co} / \mathrm{Pt}$ and $\mathrm{Co} / \mathrm{Au}$ adapted from Ref. [3] as a function of $t_{\mathrm{NM}}$. 